\title{
Pre-eclampsia and eclampsia: global challenges in low resource settings complete with proposed interventions in rural Haiti
}

\author{
Rachel M. Bender, BA ${ }^{1}$ Ginny L. Ryan, MD, MA ${ }^{2}$ \\ Keywords: pre-eclampsia, eclampsia, developing countries, health services
}

\section{Case Report}

$H W$ is 22-year-old G3P1 ill-appearing Haitian female. She presents to a local mission center holding her gravid abdomen and complaining of "doulé akouman", or sharp labor pains. The mission offers little more than an exam table and several shelves of basic medications. Several female community health agents (CHA) staff the "clinic" once a week to do blood pressure checks and bridge the care between visiting teams of American physicians. CHAs are community laypersons trained to do public health education and check vitals. Fortunately, today an American medical student and resident physician are also present. Suspicious of the pains and swollen appearance of the woman, they take a blood pressure and dip her urine. This reveals a blood pressure of 200/110 and 4+ proteinuria. On exam, a transverse incision is evident which elicits a history of aCsection. She has an unknown gestational age, zero prenatal care, and is currently contracting. The nearest hospital is a 40-minute "taptap" ride away, which she cannot afford.

\section{Introduction}

Preeclampsia is a complex multipathway disease process diagnosed by hypertension with two readings of systolic blood pressure $\geq 140 \mathrm{mmHg}$ and/or diastolic BP $\geq 90 \mathrm{mmHg}$, separated by a 4-6 hour period, and proteinuria with a urine dipstick of $\geq 1+$ or $\geq 300 \mathrm{mg}$ per 24 hours, after 20 weeks' gestation in a previously normotensive patient. Eclampsia, new onset of grand mal seizures during or after pregnancy without any other identifiable cause is one risk that can follow the diagnosis of pre-eclampsia. The overall risk of seizure is $1 \%$, and is preventable with use of Magnesium Sulfate in women with severe preeclampsia, such as this patient. Severe preeclampsia is defined as a systolic BP $\geq 160 \mathrm{mmHg}$ or diastolic BP $\geq 110 \mathrm{mmHg}$, measured twice at least 6 hours apart or evidence of other end organ damage, including presence of

\footnotetext{
${ }^{1}$ Roy J. and Lucille A. Carver College of Medicine, The University of lowa, lowa City, lowa, USA.

${ }^{2}$ The Department of Obstetrics and Gynecology, Roy J. and Lucille A. Carver College of Medicine, The University of lowa, lowa City, lowa, USA.

Please cite this paper as: Bender RM, Ryan GL. Pre-eclampsia and eclampsia: global challenges in low resource settings complete with proposed interventions in rural Haiti. Proc Obstet Gynecol. 2013;3(1): Article 1 [ 6 p.]. Available from: http://ir.uiowa.edu/pog/. Free full text article.
}

Corresponding author: Rachel Bender, 563-590-3898, rachelmarybender@gmail.com

This is an Open Access article distributed under the terms of the Creative Commons Attribution 3.0 Unported License (http://creativecommons.org/licenses/by/3.0), which permits unrestricted use, distribution, and reproduction in any medium, provided the original work is properly cited. 
renal failure, liver dysfunction, central nervous system disturbance, pulmonary edema, or right upper quadrant pain.

Ninety-nine percent of pregnancy related deaths occur in middle and lowincome countries (LMIC). Of these deaths, the World Health Organization (WHO) ranks pre-eclampsia and eclampsia as the second leading direct cause of maternal morbidity and mortality, behind only postpartum hemorrhage. A woman born in a developing country has a seven times greater risk of developing pre-eclampsia and a three times greater risk of progressing to eclampsia. Within the realm of eclampsia, she has roughly a fourteen times greater risk of death. Additionally, infant mortality in women with preeclampsia is 3 times higher in LMIC than in high-income countries. While this journal's special issue addresses advancements in our scientific understanding of preeclampsia, this paper seeks to review what we know about the basics of detection and management to encourage thoughtful applications in improving the global burden of preeclampsia and eclampsia in low resources settings.

\section{Access Limitations}

The patient is known to live 25 miles away, but to cover this mountainous distance requires hours of travel on either donkey or motorcycle on unpaved, narrow mountain passages. She came to this mission because she knows sometimes the "blan" (White) doctors are here. The public hospital is another 30 minutes away, but she is hesitant to go because she knows she will have to bribe the nurses to be seen by a physician, and the cost of a csection is more than she makes in a month.

The majority of maternal morbidity and mortality is due to limited access of prenatal care and obstetrical intervention. In high-income countries, $98 \%$ of women report having at least one prenatal visit, compared to only $68 \%$ in LMIC. A further dichotomy exists in rural vs urban settings worldwide. The WHO sets a standard goal of at least four prenatal visits. Only $61 \%$ of women in urban areas and $39 \%$ of women in rural areas meet this goal. Common barriers to care include traveling long distances, fees, childcare, financial autonomy, and a shortage of providers, especially female. These same barriers prevent women from delivering at a health facility. A survey in 41 LMIC showed that nearly a quarter of women said they did not go to the health facility for delivery because a male provider staffed it. Even among the $68 \%$ of women obtaining a prenatal visit, further barriers exist in diagnostics. One study found that $15-30 \%$ of women obtaining prenatal care never had their blood pressure checked. The WHO recommends urine dipsticks for proteinuria only in nulliparous women or those with a history of pre-eclampsia. Limitations in proper point of care testing include cost and availability of dipsticks, as well as proper training and equipment to accurately measure blood pressure.

\section{Diagnostics}

HW noticed swelling in her hands and feet several weeks ago, but a community elder told her it was normal and gave her an herbal tea to help the 
symptoms. She never saw a health care provider for prenatal care, and planned to deliver the child at home with a community midwife -- a locally appointed woman with no formal training.

Diagnostic limitations mean that a careful physical exam and early recognition of physical findings is vital in these situations. Educating women and midlevel community providers to recognize acute onset edema may reduce complications and delays. One interesting "mom-edema-meter" prototype has been proposed in the form of a wristband that is comfortable yet snug enough to quantify expansion caused by edema. When specified measurements are reached, the woman has been told to seek further medical care.

Another effective strategy in diagnosis is utilizing community health workers as liaisons between rural communities and nearby hospitals. Community health workers are lay members of the community who work within the local health system with the advantage of working more intimately with community members and sharing cultural traditions. If they can be trained and equipped to obtain basic pressure and protein studies at home visits, they can work within the local health system and prearrange necessary triage and transport.

Modern communication technologies are a promising tool for assisting the community health worker. People in LMIC have increasing access to cellular technologies, offering a much wider reach for communication of public health messages. These telecommunication strategies range from simple as generic text reminders to complex patient sensors to monitor vitals at home and report them to a central hub which can be overseen my medical professionals.

\section{Interventions}

The patient is moaning in pain, so the American doctors work fast. Luckily, there is one vial of magnesium sulfate on the dusty shelf along with a liter of intravenous fluids. Before intravenous access can be achieved, HW begins to seize. While the family medicine resident stabilizes the patient, the medical student runs down the road looking for the nearest "tap-tap" to provide public transportation to the public hospital. Ambulances in this town are only called to haul away dead bodies.

Even when pre-eclampsia is diagnosed, further hurdles exist in obtaining the necessary emergent interventions. If community health workers serve as the first point of contact for many women, the ideal antihypertensive treatment would be an oral medication with one time dosing. Insufficient evidence exists to support use of oral medication in severe hypertension of pregnancy. Even notoriously cheap and effective magnesium sulfate is underutilized due to limited supply, limited provider knowledge and training, fear of administration due to limited monitoring, and lack of national protocols. Evidence-based information dissemination is needed.

\section{Prevention}

Without adequate antenatal care and imaging, effective prevention strategies 
are of great value. Aspirin is associated with a $10-19 \%$ reduction in preeclampsia, and a $10-16 \%$ decrease in perinatal morbidity and mortality in women determined to be at "moderate to high risk" by their medical, obstetric, and family histories as well as ultrasound findings. Identifying these moderate-high risk groups may be difficult, as most women have at least one risk factor (both multiparity and nulliparity are listed as risks). Even this small reduction in incidence has the potential to make a great impact on women who may otherwise have no monitoring. The low cost and safety profile of the drug are encouraging for application in routine $\mathrm{OB}$ care in low resource settings. There is some evidence to suggest a preventative role for calcium, especially in nutrient deficient women with hypocalcaemia at baseline. Randomized controlled trials are underway, and several initiatives have been proposed to refine the large, chalky tablets into a lower-cost, smaller, and more appetizing version. In Haiti, over-the-counter "Tums" are more readily available and comfortably utilized in both market and clinical settings. These small preventative measures have the potential to make a large impact on patients like the one featured in this article.

\section{Conclusions}

HW was carried unwillingly into the back of a truck, where an IV was started to administer fluids and magnesium sulfate. 40 minutes of bumpy driving with the sick mother finally paid off when they reached the Cuban physician staffing the public clinic. Fortunately, her blood pressure was controlled with IV labetolol; she was continued on magnesium and had no further seizures. She vaginally delivered a small baby boy, and was able to follow up with the CHAs for blood pressure checks each week.

The need for prevention, detection, and treatment of pre-eclampsia is immense, especially in low income countries like Haiti. While lowa City boasts 52 physicians per 10,000 people, in Haiti (just a several hour flight away) the ratio is 10 physicians per 10,000 people. Haitian obstetrical practices and maternal and infant health are particularly concerning. During childbirth, only $1 / 4$ Haitian women will have a "skilled" attendant at her side, and three of every 1000 will die during the process. We have developed amazing technologies in the field of women's health, but if only a few women have access to them, are we really doing a service to women of the world? Few interventions have a greater impact than basic prenatal care: a physical exam in educated hands, cheap medications, and diagnostics as simple as a sphygmomanometer and urine dipsticks. As women's health professionals, we must be more proactive in sharing our wealth of educational opportunities and advocating for the underserved women of the world.

\section{Biography}

Rachel Bender is a fourth year medical student at the University of lowa, pursuing a career in Ob-Gyn with an interest in international women's health. She has been active in a locally grown organization called "Community Health Initiative, Haiti" (CHI) which is dedicated to meeting the health needs of 
underserved Haitians. $\mathrm{CHI}$ visits the same Haitian communities every three months with a full medical team, and pays monthly stipends to five local women to work as Community Health Agents to deliver basic health education and services. The urgency and danger of the case profiled in this article hit close to home for Rachel and other $\mathrm{CHI}$ providers, sparking a drive to push for more aggressive prenatal care measures. Rachel and $\mathrm{CHI}$ colleagues have worked closely with these women to perform and document at least four routine prenatal home visits equipped with urine dipsticks, blood pressure cuffs, and knowledge. $\mathrm{CHI}$ is working to obtain evidence to support these measures, and has recently launched a new electronic medical records system for use at quarterly clinics. A long-term goal is to incorporate data from health worker home visits into the system for improved patient monitoring.

$\mathrm{CHI}$ offers opportunities for health professionals and students to share their talents through clinical service and community education. All local community members are welcome to be involved in the Community Health Initiative, lead locally by UI physicians Dr. Chris Buresh, Dr. Ginny Ryan, and a supporting group of students. Please contact $\mathrm{CHI}$ or Rachel if you are interested in getting more involved!

\section{Community Health Initiative, Haiti www.Chihaiti.com chi.uiowa@gmail.com}

\section{References}

1. Turner JA. Diagnosis and management of pre-eclampsia: an update. Int $\mathrm{J}$ Womens Health. 2010 Sep 30;2:327-37. PubMed PMID: 21151680; PubMed Central PMCID: PMC2990902. doi: 10.2147/IJWH.S8550

2. WHO: The World Health Report 2005: Make every mother and child count. Geneva: World Health Organization, 2005.

3. Khan KS, Wojdyla D, Say L, Gülmezoglu AM, Van Look PF. WHO analysis of causes of maternal death: a systematic review. Lancet. $2006 \mathrm{Apr}$ 1;367(9516):1066-74. PubMed PMID: 16581405.

http://dx.doi.org/10.1016/S0140-

6736(06)68397-9

4. Altman D, Carroli G, Duley L, Farrell B, Moodley J, Neilson J, Smith D; Magpie Trial Collaboration Group. Do women with pre-eclampsia, and their babies, benefit from magnesium sulphate? The Magpie Trial: a randomised placebocontrolled trial. Lancet. 2002 Jun 1;359(9321):1877-90. PubMed PMID: 12057549.

http://dx.doi.org/10.1016/S01406736(02)08778-0

5. Abdou-Zahar C \& Wardlaw T. Antenatal care in developing countries: Promises, achieveents, and missed opportunities: an analysis of trends, levels and differentials, 1990-2001. World Health Organization; 2003.

6. Lee AC, Lawn JE, Cousens S, Kumar V, Osrin D, Bhutta ZA, Wall SN, Nandakumar AK, Syed U, Darmstadt GL. Linking families and facilities for care at birth: what works to avert intrapartum-related deaths? Int J Gynaecol Obstet. 2009 Oct;107 Suppl 1:S65-85, S86-8. PubMed PMID: 19815201; PubMed Central PMCID: PMC3428847. doi: 10.1016/j.ijgo.2009.07.012 
7. Engenderhealth. Balancing the scales: expanding treatment for pregnant women with life-threatening hypertensive conditions in developing countries. May 2007. http://www.engenderhealth.org/files/pub s/maternal-health/engenderhealtheclampsia-report.pdf

8. Personal communication Harshad Sanghvi - adapted from Demographic Health Surveys. January 2011. http://www.measuredhs.com/

9. Pawluk D, Burch D, Strauss JF 3rd, Peng $\mathrm{T}$, Woodward A. The Momedemameter: An Affordable Preeclampsia Detector For Low Resource Environments. J Med Device. 2009 Mar;3(1):14501-14503. PubMed PMID: 22437036; PubMed Central PMCID:PMC3307143.

http://dx.doi.org/10.1115/1.3043791

10. Firoz $T$, Sanghvi $H$, Merialdi $M$, von Dadelszen P. Pre-eclampsia in low and middle income countries. Best Pract Res Clin Obstet Gynaecol. 2011 Aug;25(4):537-48. Epub 2011 May 17. PubMed PMID: 21592865. doi: 10.1016/j.bpobgyn.2011.04.002

11. Engenderhealth. Workshop on magnesium sulfate for the management of pre-eclampsia and eclampsia. 2007. http://www.engenderhealth.org/indexmain.php

12. Duley L, Henderson-Smart DJ, Meher S, King JF. Antiplatelet agents for preventing pre-eclampsia and its complications. Cochrane Database Syst Rev. 2007 Apr 18;(2):CD004659. PubMed PMID: 17443552.
13. Askie LM, Duley L, Henderson-Smart DJ, Stewart LA; PARIS Collaborative Group. Antiplatelet agents for prevention of pre-eclampsia: a metaanalysis of individual patient data. Lancet. 2007 May 26;369(9575):1791-8. PubMed PMID: 17512048. http://dx.doi.org/10.1016/S01406736(07)60712-0

14. Hofmeyr GJ, Atallah AN, Duley L. Calcium supplementation during pregnancy for preventing hypertensive disorders and related problems. Cochrane Database Syst Rev. 2006 Jul 19;(3):CD001059. Update in: Cochrane Database Syst Rev. 2010;(8):CD001059. PubMed PMID: 16855957.

15. Meads CA, Cnossen JS, Meher S, Juarez-Garcia A, ter Riet G, Duley L, Roberts TE, Mol BW, van der Post JA, Leeflang MM, Barton PM, Hyde CJ, Gupta JK, Khan KS. Methods of prediction and prevention of preeclampsia: systematic reviews of accuracy and effectiveness literature with economic modelling. Health Technol Assess. 2008 Mar;12(6):iii-iv, 1270. PubMed PMID: 18331705.

16. "Global Health Observatory Data Repository". [Internet] Geneva: World Health http://apps.who.int/gho/data/ 